\title{
Productivity in Gold Mining Technology
}

\author{
A RESEARCH PROGRAMME TO OFFSET INCREASED COSTS
}

\section{W. S. Rapson}

Chamber of Mines of South Africa, Johannesburg

A programme of research and development designed to increase productivity and efficiency in gold mining has been initiated by the Chamber of Mines of South Africa at a cost of between R100 million and R150 million over the next ten years. This is designed to offset rising costs by the fuller utilisation of existing equipment and by greater mechanisation in the future, as well as to ensure the continuity of supplies.

The gold resources of the Witwatersrand basin are immense. From reefs in this geological formation some thirty-two million kilograms of gold (about 1,000 million ounces) have already been extracted and there is probably more gold than this in reefs still to be mined. How is it then that with the higher price of gold the output of gold from this area, which constitutes over 70 per cent of the gold production of the Western world, has tended to decrease? What is the significance of the fact that the gold output from this area declined in 1973?

The facts are that there are a large number of mines exploiting reefs of the Witwatersrand series, that the gold content of these reefs is variable, and that many mines are thus able, by selection of the reefs and areas of reefs which they mine, to control the gold grade of the ore fed to their mills.
It is largely for this reason that such mines were able to survive over the years during which the price of gold was fixed, but during which costs were steadily rising and mines becoming deeper. During this period they were able to increase the average grade of ore mined to offset increases in costs. The implications of this for the industry as a whole were, however, serious since it resulted in large areas of 'undergrade' or 'non-pay' reef being left unmined. The lives of the mines were being progressively shortened.

The increased price of gold has meant, however, that most mines have been able to lower the average grade of the ore which they mine. In 1973, for example, this average grade was decreased by an average of 10 per cent. Even though the actual tonnage of ore milled was increased from seventytwo to seventy-five million metric tons, this meant that overall gold output decreased by 6 per cent.

The higher price for gold is therefore having the unexpected effect-in the short-term-of decreasing the availability of gold from this major source of supply. In the longer term, however, it should ensure the fuller exploitation of the reefs of the Witwatersrand basin and therefore stabilise the supply of gold from this source much further into the future.

Over the past few years mining costs have been steadily rising and mines have become deeper. These surface installations are at one of the newer mines on the Witwatersrand, Western Deep Levels, where operations are now being carried out at depths hetween 3,500 and 4,000 metres, with increasingly complex technical problems arising. The intensified programme of research into productivity that has been mounted is designed to increase the efficiency of mining methods, to maintain the high level of gold production that is required, and to combat rising costs

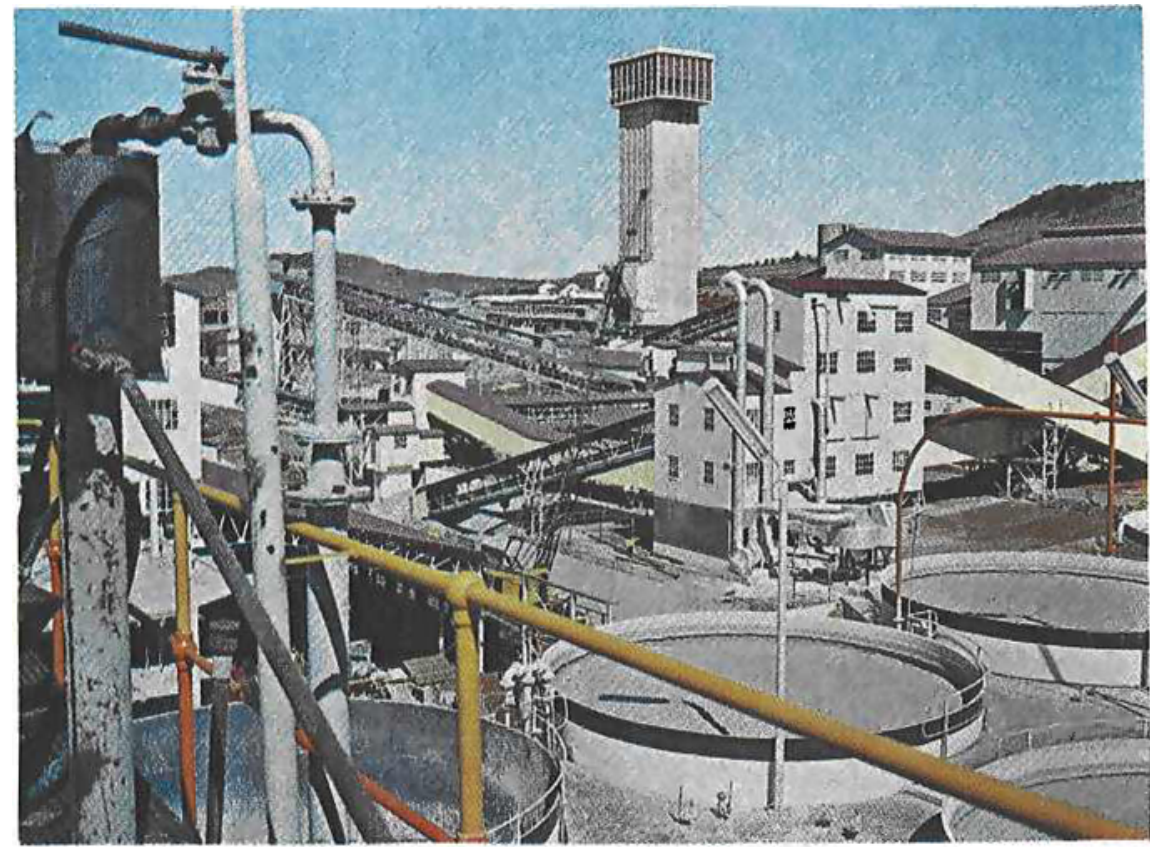




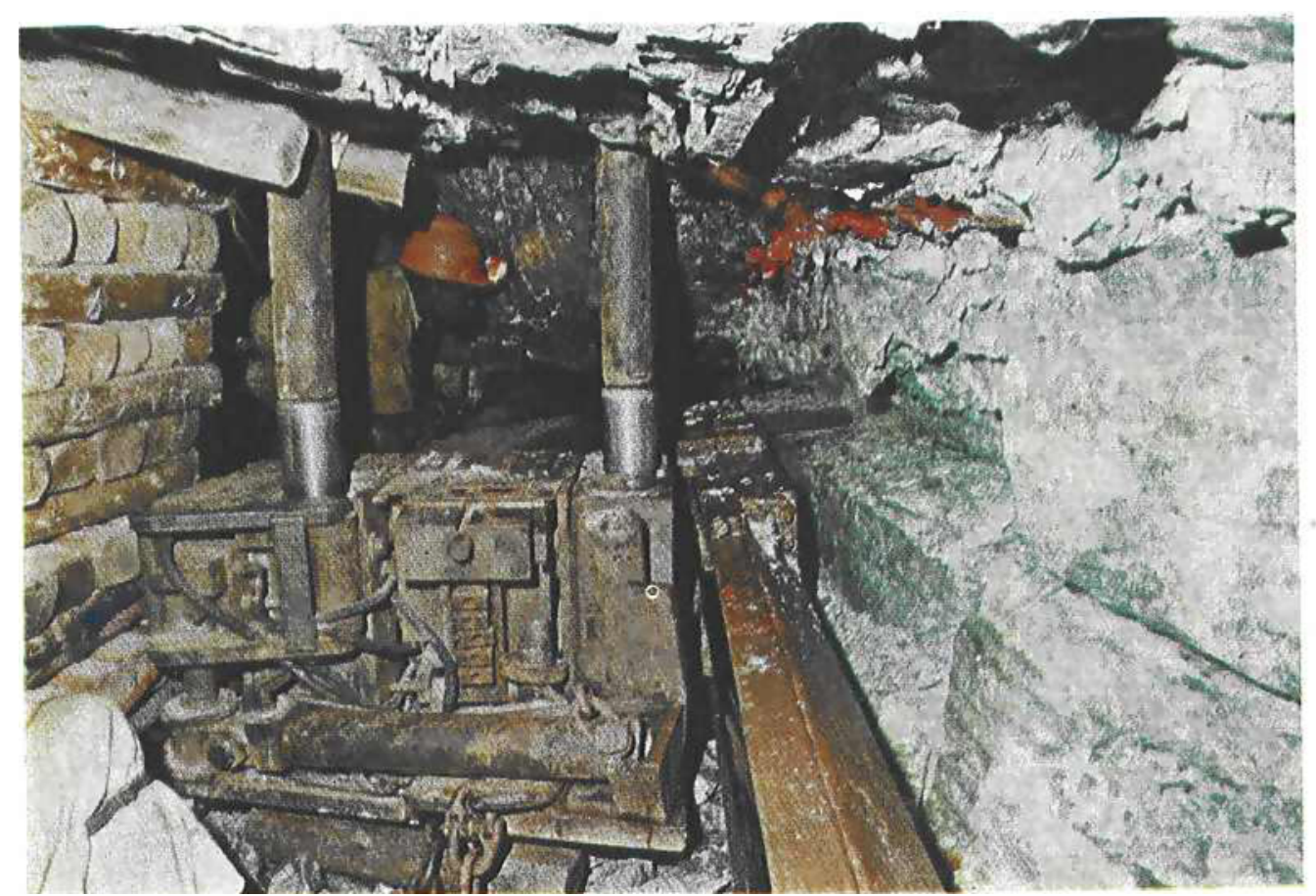

Over the past twenty to thirty years there has been a major break-through in coal-mining productivity through the introduction of mining systems using mechanised methods of excavation. The development of the equipment that will make it possible to use similar systems for excavating the hard quartzitic rocks of the Witwatersrand is a major objective and prototype rock-cutting machines, such as that shown here, have already excavated considerable areas of the gold-bearing reef in field trials. These and other developments are being vigorously pursued

Since current inflationary trends could nullify these effects, great importance is attached at present to increasing productivity in the industry in all spheres, and a campaign aimed at optimising the use of men, money, minerals, materials, and machinery throughout the industry is in progress. In the technical sphere, for example, a determined effort is being mounted to achieve major breakthroughs in the mechanical mining of the hard quartzitic reefs and in the control of rock stress and other environmental factors at depth. The efforts concentrated in this area recently by both the mining houses and the mines, and by the Research Organisation of the Chamber of Mines, are to be more than doubled.

In view of the success achieved in these areas to date, there is good reason to anticipate that gold will continue to flow from the mines of the Witwatersrand for very many years to come.

\section{High Speed Gold Plating of Integrated Circuits}

High yield with high reliability at low cost represent the ideal conditions for success in the production of beam lead integrated circuits. The selective gold plating of a wafer containing several hundred circuit chips is a critical part of the total processing in which a number of defects may give rise to rejections-lateral deposition of gold under the photoresist, too heavy or "spiky" deposition above the plane of the conductor paths, edge build-up, or non-adherence of the gold due to particles of photoresist depositing themselves on to a gold path or beam.

A new process aimed at providing a superior quality of gold plating with increased yield has been developed at Western Electric's Allentown Works and has been described by the engineer responsible for its initiation, Edward S. Figuli (Western Elect. Eng., 1974, 18, (1) 18-24). In this process, which has been given the, name "Velocity Gold Plating", a highly conductive electrolyte is used which permits of a considerable increase in current density. This is caused to impinge upon the surface to be plated at high speed, so that depletion of the cathode layer is avoided. Several electrolytes were investigated, but optimum results were obtained with an organic phosphate solution. A flow rate of around 8 litres per minute was found to be most satisfactory, but direct current plating was not so successful as a square wave periodic-reverse current; a ratio of forward to reverse current of about 30 to 1 gave the best results.

This high-speed method, now in production, has shown substantial improvements in chip per wafer yield-as much as 56 per cent greater than by normal plating practice-as well as greater ease of handling wafers and a shorter plating time. 